\title{
GENERATOR AND PRIME MOVER CAPACITIES
}

BY

DAVID B. RUSHMORE and ERIC A. LOF

Presented under the auspices of the

\section{Standards Committee}

A. E. KEN NELLY, Chairman, Harvard University, Cambridge, Mass. COMFORT A. ADAMS, Secretary, Harvard University, Cambridge, Mass.

W. C. L. EGLIN, Philadelphia, Pa.

W. S. MOODY, Pittsiield, Mass.

H. W. FISHER, Perth Amboy, N. J.

W. H. POWELL, Milwaukee, Wis.

E. R. HILL, New York. Charles ROBbINS, Pittsburgh, Pa.

PETER JUNKERSFELD, Chicago, Ill. CHARLES F. SCOTT, New Haven, Conn.

B. G. LAM ME, Pittsburgh, Pa. J. FRANKLIN STEVENS, Philadelphia, Pa.

W. L. MERRILL, Schenectady, N. Y. CHARLES P. STEINMETZ,Schenectady,N.Y SAMUEL W. STRATTON, WASHINGTON, D. C. 


\title{
GENERATOR AND PRIME MOVER CAPACITIES
}

\author{
BY DAVID B. RUSHMORE AND ERIC A. LOF
}

\begin{abstract}
Paper
Electric generators are of necessity driven by prime movers and the combination must be treated as a single unit when considering the questions of ratings and capacities. The importance of the proper adaptation of the capacities is fully emphasized by the fact that there are in operation in many stations in this country, units in which the output is unnecessarily limited by a discrepancy in the ratings, in that the prime mover is either too small or too large for the generator. The latter may, for example, be designed for unity power factor, while the actual operating power factor may be 0.8 , in which case the full capacity of the prime mover can not be utilized.

In the past every effort was made to adjust the ratings of the generators to the station load curves, and the result was that overload capacities of 25, 50 or even 100 per cent had to be guaranteed, usually for a period of two hours. With the growth of the generating station and the improved load conditions this practice is now becoming more and more obsolete and the units are being rated on a maximum or, more properly called, constant continuous rating, which should not be exceeded except during momentary peaks. Steam turbine units have been rated according to this method for some time past, and with entirely satisfactory results. It is also becoming quite common in connection with waterwheel-driven units, and there seems to be no reason why it should not prove to be equally satisfactory for hydroelectric plants, especially for low heads, where the waterwheel efficiency falls off rapidly as the power is reduced below the normal full load. Exceptions to this may, however, be found, as, for example, where heavy short-period peak loads must be provided for, in which case it may be advisable to select a generator having a corresponding overload capacity. For the sake of standardization it seems, however, desirable to give all generators a maximum constant continuous rating at a certain specified temperature.
\end{abstract}




\title{
GENERATOR AND PRIME MOVER CAPACITIES
}

\author{
BY DAVID B. RUSHMORE AND ERIC A. LOF
}

The chief distinctive characteristic of electrical apparatus is that its capacity is limited by thermal considerations. Electrical generators are of necessity driven by prime movers and the combination must be treated as a single unit when considering the questions of ratings and capacities. Such prime movers as steam engines, steam turbines, gas engines and waterwheels have various limitations regarding their output which must be considered in connection with that of the electric generators they are driving. The proper adjustment of ratings for generators and prime movers with these different limitations as determined by the conditions of service, is the object of this paper. In direct-current generators the limitation imposed by commutation has almost entirely been removed by the use of interpoles. With alternators as now constructed, the limitation of output due to regulation of the machine is but seldom found; therefore the question of heating may be considered as the important factor for consideration. Under certain conditions of violentiy fluctuating loads or intermittent service, the questions of commutation and regulation may, however, become of considerable importance.

The capacity of an alternator is limited not only by the actual energy load which the machine is carrying, but also by the power factor of such load. The additional heating at low power factors and constant power is due to the wattless component of the armature current and also to the additional field current necessary to counteract it. In many cases it is possible to predetermine approximately the power factor under which the generators will operate, and the special design to meet this 
particular condition is largely desirable. The curves in Fig. 1 show the different conditions of load and power factor which will produce the limiting conditions of heating in an inductor alternator. The synchronous impedance here is considered to consist almost entirely of reactance.

The importance of the proper adaptation of capacities of generators and prime movers is emphasized by the fact that there are in operation in many stations in this country units in which the output is unnecessarily limited by an improper rating

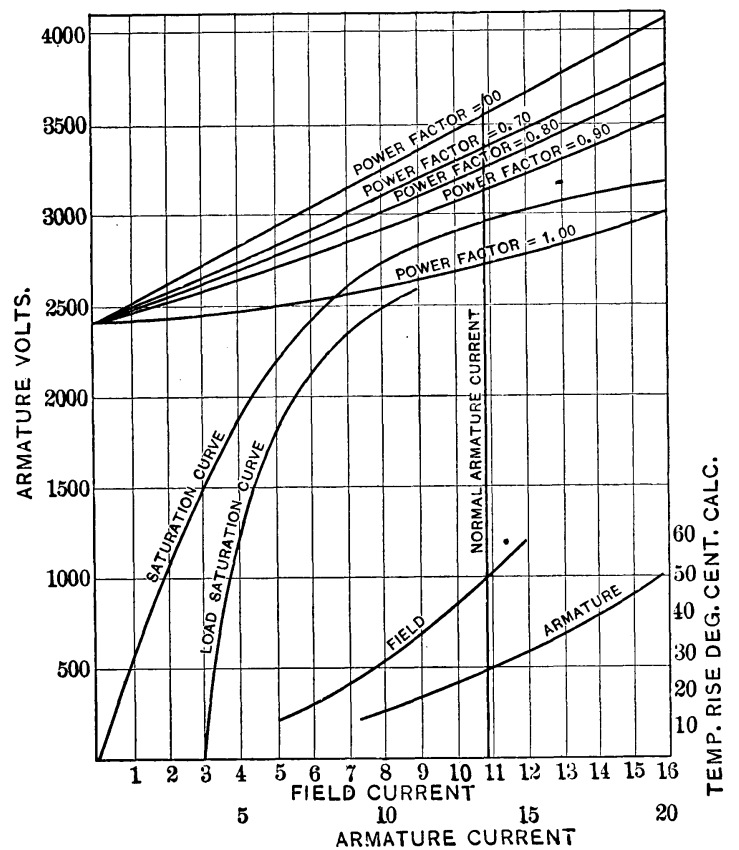

Fig. 1-Characteristic Curves of Induction Alternator.

or design of either the generator or prime mover. The generator may be designed for unity power factor while the condition of operation may be the power factor 0.8 , in which case only a part of the prime mover capacity can be utilized. In not a few instances in hydroelectric stations, the waterwheel is either too small or too large for the generator and a like result ensues. In some hydroelectric plants where the generators are installed to handle peak loads, this maladjustment of ratings is a necessity, but with most of the larger systems it is unnecessary to run machines 
except at or near their maximum ratings. In the past, every effort was made to adjust the ratings of generators to the load curves and we had 25, 50 and 100 per cent overload guarantees for certain apparatus. Experience and better load conditions have changed this to a maximum rating which has become possible largely through the growth in the size of stations and systems.

The speeds of engine-driven units, both gas and steam, have become nearly standardized, and turbine-driven sets are rapidly approaching the same condition. With waterwheel units, however, the situation is such that the capacity and speed of the generator is often determined largely by the hydraulic conditions and the characteristics of the waterwheel which is to be used.

With steam engines the point of maximum efficiency is rather marked, as shown in the curve of Fig. 2, and the ratings are

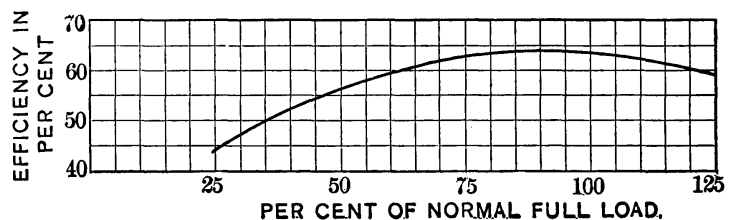

Fig. 2-Performance Curve of 800 h.P. Compound Condensing Gas Engine.

usually such that the engine is working under its most economical load at the rating of the electrical generator. With gas engines, however, the efficiency increases with the load beyond the capacity of the engine, as shown in Fig. 3, and for this reason the rating of the engine is generally made as nearly as possible to its maximum capacity, leaving a small margin for regulating purposes. With the steam turbine, Fig. 4, the efficiency curve is usually so flat that it is a question of desirable overload capacity which limits the rating of the turbine.

In the waterwheel unit, the efficiency usually falls off rapidly above and below the maximum point, so that the rating of the generator should correspond to the point of maximum efficiency of the water wheel. Steam engines and steam turbines are designed to operate with certain variations both in pressure of the steam and conditions of vacuum. Gas engines must accommodate themselves to variation in the quality of the gas. 
With the waterwheels, however, by far the large majority of installations are subject to a change in head which varies over a wide percentage. In many of the low head installations the back water may bring about a change in head which is beyond the capacity of one wheel to accommodate, and in some plants additional wheels must be mounted on the same shaft and cut into service at times of low head. One particular instance of this kind is the plant of the Chattanooga and Tennessee River Power Company, where the head may vary from 20 to $42 \mathrm{ft}$. $(6.1$ to $12.8 \mathrm{~m}$.). In most of the large developments this change in head is the limiting feature in the design of the water wheel as related to the generator capacity, for in all electrical work it is necessary that the speed of the generator be kept constant.

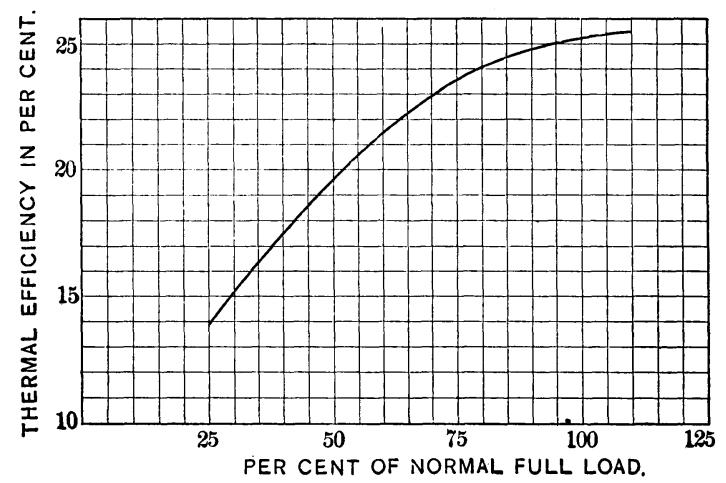

Fig. 3-Performance Curve of 2000-h.P. Gas Engine

Waterwheel runners of different designs are compared on the basis of their specific speeds. The specific speed of a waterwheel is the number of revolutions per minute at the point of maximum efficiency that a similar wheel will give when it delivers one horse power under one meter head. By comparison of the specific speeds we can judge of the characteristics of waterwheel runners without respect to their actual speed, power or head. A high specific speed means a high actual speed, and a low specific speed means a low actual speed in revolutions per minute. For this reason waterwheels with low specific speeds are generally used with high heads in order to make the speed of the generator within the range of good electrical design.

Waterwheels with high specific speeds have very deep runne vanes, and these are liable to erosion under high heads; also, 
the efficiency curves of high specific speed runners are more pointed than with the low specific speed type, and this allows a narrower margin for operation under the best conditions. This is clearly shown in curves in Fig. 5 .

The maximum full load capacity or a turbine is that point beyond which the output decreases with an increase in gate opening. The margin between the point of maximum efficiency and of maximum capacity depends upon the specific speed of the runner, and is smaller the higher the specific speed. This is illustrated in Fig. 5, which shows that as the specific speed is increased the point at which maximum efficiency occurs approaches nearer to the power delivered at full gate opening. The specific speed may thus be increased to such an extent that the point of maximum efficiency and maximum output coincide. With low heads and high specific speeds it is therefore desirable

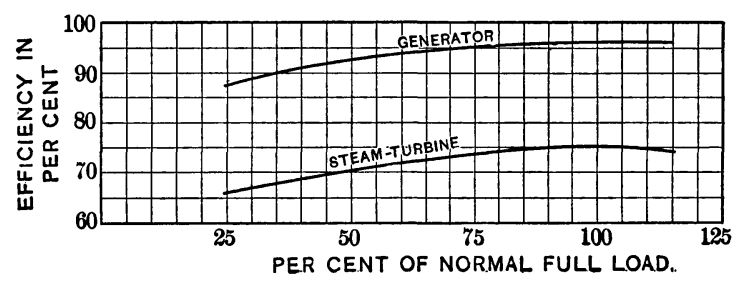

Fig. 4-Performance Curves of 5000-kv. Steam TurboGenerator SeT

to operate wheels near their point of maximum output, and to obtain the best results the generator should be designed giving consideration to this point.

Referring again to the curves in Fig. 5, it will be noted that the full load capacity occurs at about 6 per cent above normal or rated full load in all three cases. This is in accordance with the general practise, the margin being allowed for governing. It is also noted that for curves $B$ and $C$ the efficiency is falling off very rapidly at 6 per cent overload, and that should the gate be opened stili further the output would reduce instead of increase. If with low specific speed wheels, as represented by curve $A$, the gates were still further opened, the power would continue to increase to some extent.

The point of maximum efficiency for wheels represented by curve $A$ occurs at about 90 per cent of normal full load, in the case of $B$ at 93.5 per cent, while in the case of $C$ the maximum 


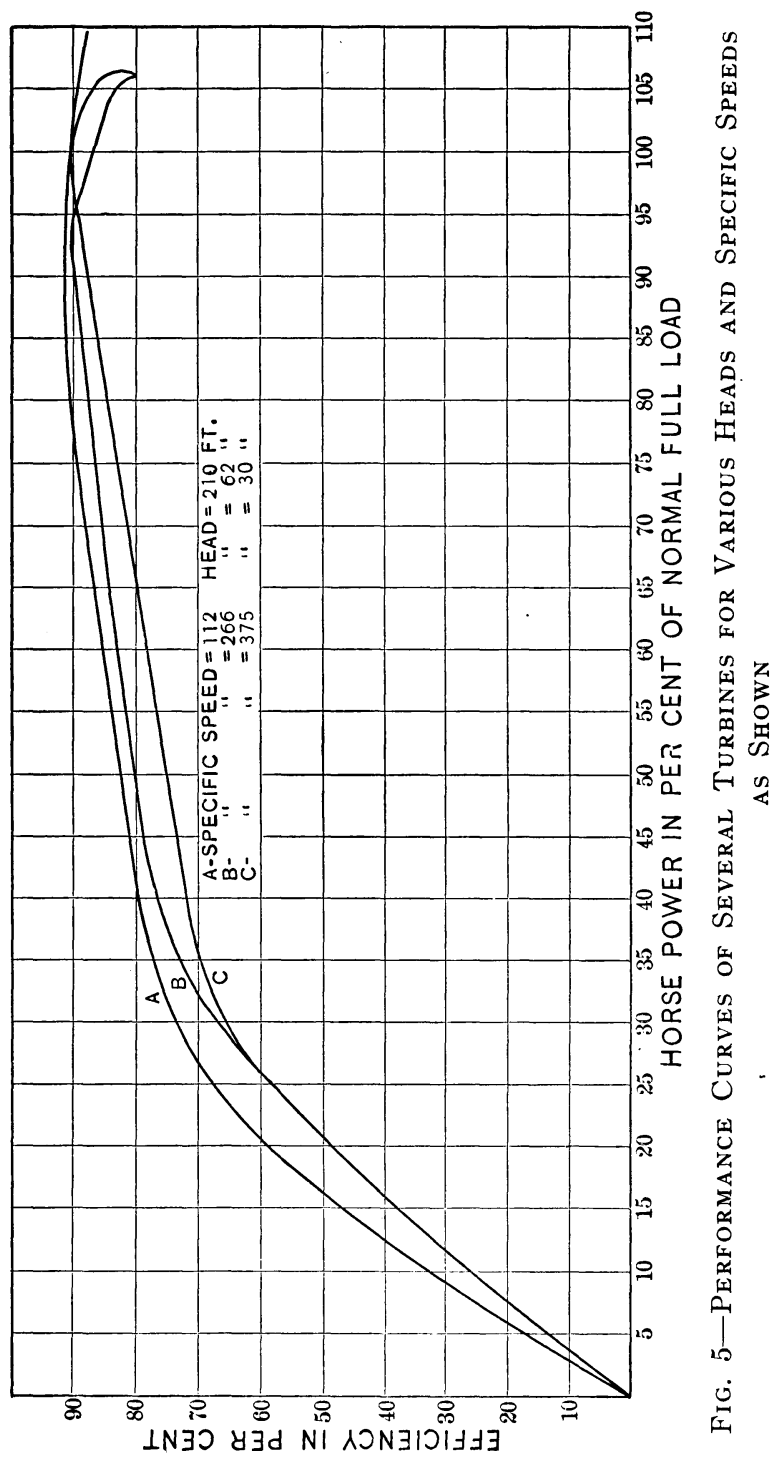


efficiency occurs just at the point of normal or rated full load. Thus, as stated before, the power at which the maximum efficiency occurs approaches nearer to full load as the specific speed increases.

With high head wheels, as represented by curve $A$, the effciency remains very high over a very large range in power, while for low head wheels, curve $C$, the efficiency falls off rapidly as the power is reduced below the normal full load. For this reason it is desirable to run low head wheels under practically full load conditions. With high head wheels this is not so important, as the efficiency is still high at partial loads. With wheels as represented by curve $C$, it is also necessary to allow some margin above the normal full load for governing, as it is desirable to operate the turbine at its point of maximum efficiency With high head wheels, curve $A$, such a margin need not be allowed.

The curves plotted in Fig. 5 represent operating conditions under constant head. This, however, is not always realized, especially in low head plants where floods and dry seasons sometimes cause quite a variation in the head, and this has, as previously mentioned, quite a bearing on the selection of the waterwheel, and should therefore be given careful consideration.

If the speed of the unit could be allowed to vary at all times as the square root of the ratio of the heads the shape of the performance curve for any head other than normal would be the same as that secured at normal head, but the output would vary as the $3 / 2$ power of the ratio of the heads. In the case of wheels driving alternating-current generators a speed variation is not permissible and the speed must be kept constant irrespective of any variation in head which may occur.

In Fig. 6 is plotted a set of curves illustrating the effect of a varying head. A 10,000-h.p. turbine is assumed to operate normally under a 32 -ft. $(9.75-\mathrm{m}$.) head, the speed to be constant for a range of heads from 26 to $38 \mathrm{ft}$. (7.92 to $11.6 \mathrm{~m}$.). As the head goes up to $38 \mathrm{ft}$. (11.6 m.) the shape of the curve approaches more closely curve $B$ in Fig. 5 , while when the head falls to 26 ft. $(7.92 \mathrm{~m}$.), the speed being constant, it approaches more closely to curve $C$. In other words, when operating under a 38 -ft. (11.6-m.) head, the speed is lower than the best speed for the runner under that head, while when operating under the $26-\mathrm{ft} .(7.92-\mathrm{m}$.) head, the speed of the wheel is higher than the best speed. Under $38 \mathrm{ft}$. (11.6 m.) head the point of maximum 


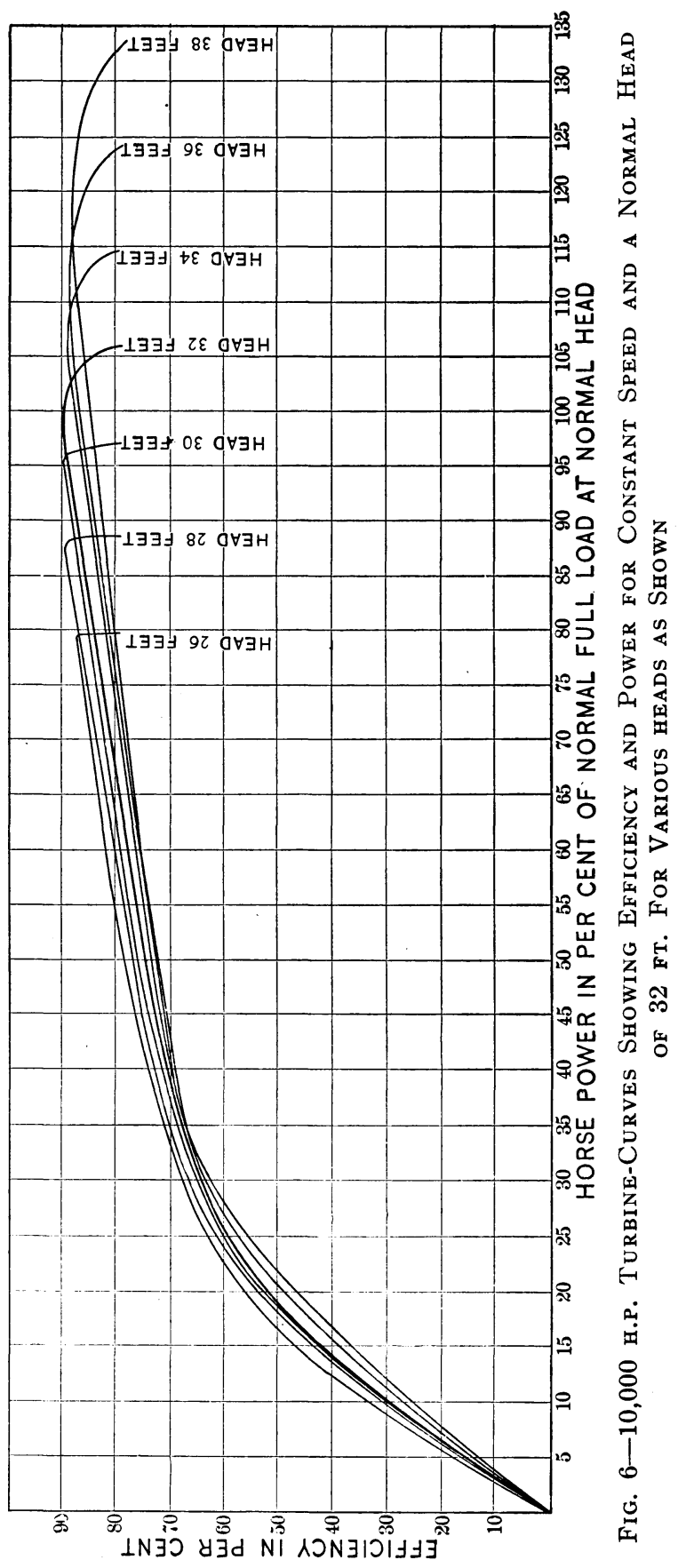


efficiency is, furthermore, considerably below the normal full load at that head, while under $26 \mathrm{ft}$. $(7.92 \mathrm{~m}$.) head the power at which maximum efficiency occurs is the actual full load, illustrating the points discussed above in reference to the relation of the power at which maximum efficiency occurs and the normal full load power for various specific speeds.

Let us assume that a selection of a wheel is to be made for an installation, and that performance curves are desired, showing the expected efficiency for various loads and speeds. Curves $A, B$ and $C$ in Fig. 5 may each represent a possible curve, dependent upon the revolutions selected for the turbine in question, the revolutions being directly proportional to the specific speeds, and they will illustrate the manner in which the efficiencies at partial gate openings will fall off in any one

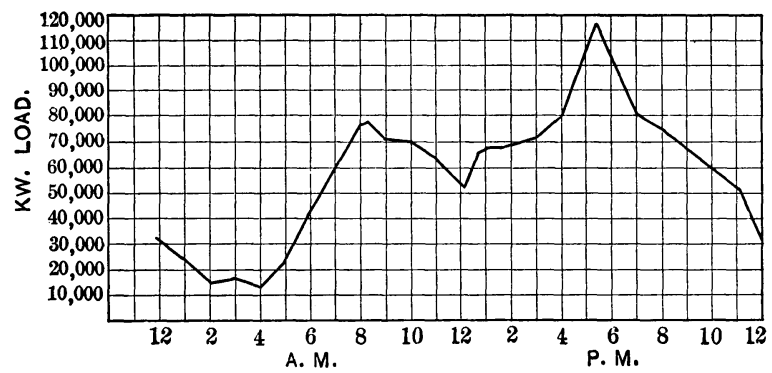

Fig. 7-Typical Load Curve of Large Central Station-December LOAD

case, depending upon the actual revolutions per minute selected for the design of the wheel. They will also give an idea as to the margin between the normal full load and the power at which the point of maximum efficiency will occur. In the selection of a speed for any installation, therefore, aside from the cost of the generators, the question of the wheel efficiencies at partial gate openings has a considerable bearing. Where a unit is likely to operate under a very wide range in power, it would be advisable to select a wheel represented by curve $A$, giving a high efficiency for a considerable range in power.

All power systems have a more or less varying load, and this has a very important bearing on the selection of the proper generating equipment and on the economy of the plant. The load will vary considerably, not only during the 24 hours of the 
day but also for different periods during the year. The load curve also differs materially for different kinds of load, such as for central stations, industrial establishments, street railways, etc.; a typical load curve of a central station is represented in Fig. 7.

The size and capacity of the units in a hydroelectric station is determined, in many cases, quite largely by the hydraulic conditions. In operating, the number should, wherever possible, never be less than four, unless the station forms part of a larger system. It is better to operate machines as near full load as possible, and to start new units instead of utilizing overload capacities. Where sudden overloads of considerable magnitude come on the system for very short periods it is, of course, necessary to have a wheel capacity sufficient to care for them.

The foregoing discussion indicates that waterwheel characteristics will vary with different installations. For the sake of standardization it is desirable to give the generators a maximum rating at a certain temperature. The proper relation of the capacities of generator and waterwheel should be considered for each installation. 